\title{
Технологии формообразования \\ светосильных дифракционных \\ оптических элементов на основе \\ использования делительной техники
}

маятникового типа

А.Н.Мельников, giро@telebit.ru АО «НПО «Государственный институт прикяадной оптики», Казань, Россия

\begin{abstract}
Рассмотрены особенности и ограничения технологий формообразования и перспективные области использования светосильных дифракционных оптических элементов. Для целого ряда приложений необходимо изготавливать нарезные светосильные дифракционные оптические элементы на сферических и асферических поверхностях с большой стрелкой прогиба, что на практике недостижимо с применением имеющегося технологического оборудования. Предлагаются технические решения, открывающие возможность расширить номенклатуру светосильных дифракционных оптических элементов, на основе использования делительной техники маятникового типа с последующим реплицированием дифракционной структуры в полимерном слое.
\end{abstract}

Ключевые слова: светосильные дифракционные оптические элементы, светосильные нарезные дифракционные решетки, технологии формообразования, области применения, светосильный компактный спектрограф, делительная машина маятникового типа, мастерматрица, реплицирование, фотополимеры.

\section{High-aperture diffraction optical element shaping techniques based on the use of pendulum-type ruling engines}

\section{A.N.Melnikov, gipo@telebit.ru JSC "NPO «State Institute of Applied Optics», Kazan, Russia}

This paper touches upon the features and limitations of shaping techniques and promising application ranges of high-aperture diffraction optical elements. A number of applications require manufacturing ruled high-aperture diffraction optical elements on spherical and aspherical surfaces with a large sag, which is unachievable in practice with the existing manufacturing equipment. Engineering solutions have been suggested that open up the possibility to broaden the range of high-aperture diffraction optical elements basing on the use of pendulum-type ruling engines with subsequent replication of diffraction structure in the polymer layer.

Key words: high-aperture diffraction optical elements, high-aperture ruled gratings, shaping techniques, ranges of application, high-aperture compact spectrograph, pendulum-type ruling engine, master matrix, replication, photopolymers. 
При создании компактных и светосильных аналитических спектральных приборов для решения ряда задач фундаментального, поискового и прикладного характера (фундаментальные исследования, контроль излучения плазмы, дистанционное зондирование Земли из космоса, экологический мониторинг, контроль химического состава веществ и др.) необходимо использовать отражательные и пропускающие светосильные дифракционные оптические элементы (ДОЭ) с высокой дифракционной эффективностью на выпуклых и вогнутых сферических и асферических поверхностях с большой стрелкой прогиба (большой крутизной) рабочей поверхности [1-4]. Такие дОэ обладают как диспергирующими свойствами, так и оптической силой, что позволяет минимизировать массогабаритные характеристики спектральных приборов, а также улучшить их энергетические и аберрационные характеристики.

В настоящее время ДОэ подобного типа изготавливаются на основе применения следующих технологий [5-20]:

- нарезная технология, реализуемая с использованием делительных машин и высокоточных токарных станков с числовым программным управлением;

- голографические технологии;

- фотолитографические технологии;

- 3D-технологии полимеризации в фотополимерных материалах.

В качестве иллюстрации в таблице 1 приведены параметры неплоских нарезных и голограммных дифракционных решеток стандартного ряда, предлагаемых в настоящее время в каталогах некоторых фирм; из таблицы 1 видно, что наибольшее значение стрелки прогиба рабочей поверхности для нарезных дифракционных решеток составляет 4,02 мм, для голограммных 8,02 мм. При этом, как известно, классические нарезные технологии обеспечивают достижение наибольших значений дифракционной эффективности, но уступают голограммным технологиям по светосиле.

Фотолитографические технологии на базе применения аппаратуры прямой лазерной записи обеспечивают формообразование структуры доэ на неплоских поверхностях со стрелками прогиба не более 5,2 мм $[9,20]$. Имеющиеся технологические ограничения определяются характером зависимости размера пятна рассеяния записывающей лазерной системы от изменения угла между нормалью к рабочей поверхности дОЭ и оптической

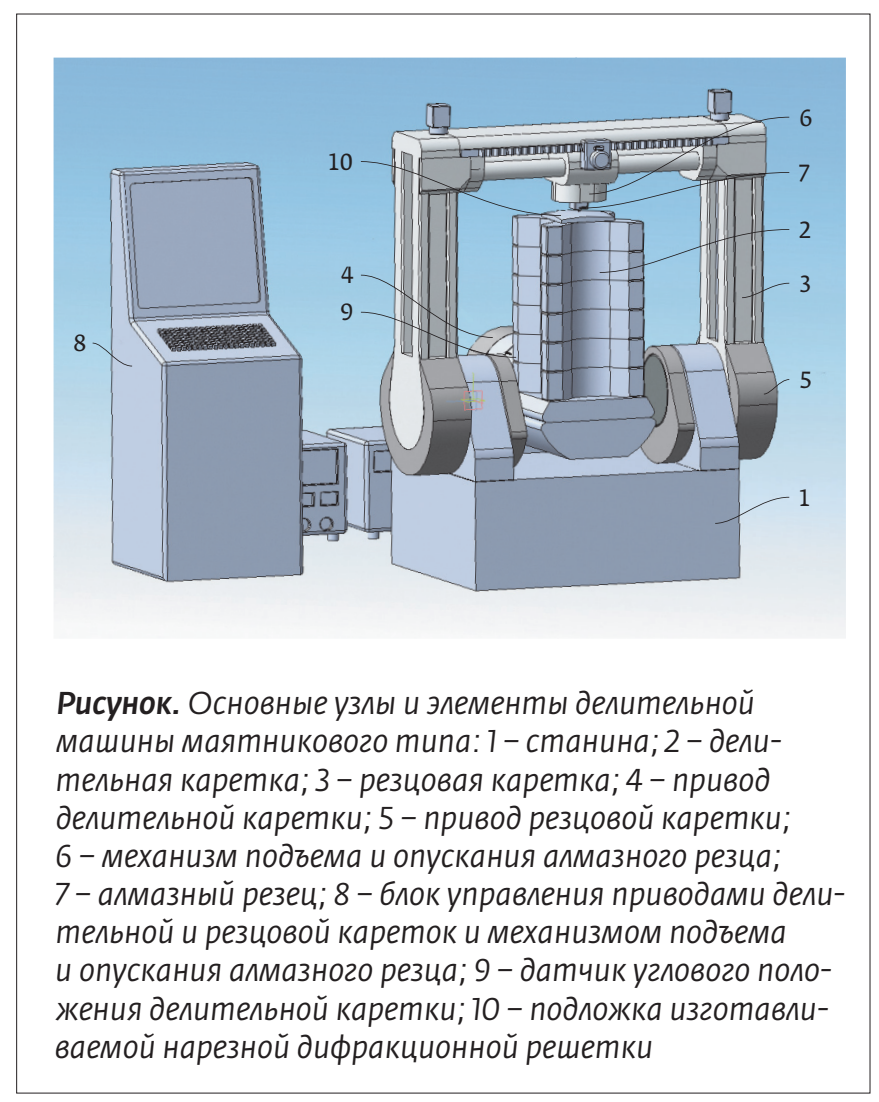

осью формирующего объектива, чувствительностью и контрастом используемого фотоматериала, что в результате вызывает неравномерность дифракционной эффективности в пределах светового диаметра ДОэ.

3D-технологии полимеризации в фотополимерных материалах позволяют получать трехмерные дифракционные структуры на ограниченном световом диаметре - в пределах нескольких миллиметров $[10,15]$.

Таким образом, в настоящее время наиболее перспективным направлением, обеспечивающим возможность создания светосильных ДОЭ с высокой дифракционной эффективностью, является реализация нарезных технологий с необходимостью разработки принципиально нового технологического оборудования.

В работе [21] рассмотрен пример расчета и оптимизации оптической схемы компактного светосильного спектрографа, построенного на основе использования вогнутой отражательной неклассической нарезной дифракционной решетки.

Оптимизированные параметры оптической схемы спектрографа следующие:

- $\quad$ пространственная частота штрихов решетки в вершине $712 \mathrm{MM}^{-1}$; 
Таблица. Современный уровень развития технологий формообразования коммерчески доступных неплоских нарезных и голограммных дифракционных решеток

\begin{tabular}{|c|c|c|c|c|c|c|}
\hline \multirow{2}{*}{$\begin{array}{l}\text { № } \\
\Pi / \Pi\end{array}$} & \multirow[t]{2}{*}{ Параметр дОэ } & \multicolumn{5}{|c|}{ 1. Классические нарезные технологии } \\
\hline & & $\begin{array}{l}\text { Аберрационно- } \\
\text { скорректиро- } \\
\text { ванные вогну- } \\
\text { тые решетки } \\
\text { для высоко- } \\
\text { разрешающего } \\
\text { монохрома- } \\
\text { тора Seya- } \\
\text { Namioka [5] }\end{array}$ & $\begin{array}{l}\text { Аберраци- } \\
\text { онно-скоррек- } \\
\text { тированные } \\
\text { вогнутые } \\
\text { решетки для } \\
\text { компактного } \\
\text { высокоэффек- } \\
\text { тивного моно- } \\
\text { хроматора [5] }\end{array}$ & $\begin{array}{l}\text { Аберраци- } \\
\text { онно-скоррек- } \\
\text { тированные } \\
\text { вогнутые } \\
\text { решетки для } \\
\text { спектрогра- } \\
\text { фов сплоским } \\
\text { полем [5] }\end{array}$ & $\begin{array}{l}\text { Выпуклые } \\
\text { решетки [6] }\end{array}$ & $\begin{array}{l}\text { Вогнутые } \\
\text { решетки для } \\
\text { спектрографов } \\
\text { на круге Роу- } \\
\text { ланда [17] }\end{array}$ \\
\hline 1.1 & $\begin{array}{l}\text { Диапазон размеров } \\
\text { рабочей поверхности, } \\
\text { мм }\end{array}$ & $\begin{array}{l}\text { от } 21 \times 16 \\
\text { до } 76 \times 72\end{array}$ & $\begin{array}{l}\text { от } 16 \times 16 \\
\text { до } 96 \times 56\end{array}$ & $\begin{array}{l}\text { от } 5 \times 5 \\
\text { до } 46 \times 46\end{array}$ & $24 \times 22$ & $\begin{array}{l}\text { от } 20 \times 20 \\
\text { до } 130 \times 120\end{array}$ \\
\hline 1.2 & $\begin{array}{l}\text { Диапазон радиусов кри- } \\
\text { визны рабочей поверх- } \\
\text { ности, мм }\end{array}$ & от 200 до 1000 & от 80 до 3000 & от 50 до 500 & от 35 до 80 & от 115 до 10685 \\
\hline 1.3 & $\begin{array}{l}\text { Диапазон стрелок про- } \\
\text { гиба рабочей поверхно- } \\
\text { сти, мм }\end{array}$ & от 0,16 до 0,72 & от 0,13 до 0,91 & от 0,06 до 0,53 & от 1,67 до 4,02 & от 0,10 до 1,88 \\
\hline 1.4 & $\begin{array}{l}\text { Диапазон простран- } \\
\text { ственных частот, } \text { мм-1 }^{-1}\end{array}$ & от 600 до 2400 & от 600 до 1200 & от 300 до 1200 & от 60 до 200 & от 75 до 3600 \\
\hline 1.5 & $\begin{array}{l}\text { Рабочий спектральный } \\
\text { диапазон, нм }\end{array}$ & $\begin{array}{l}\text { от } 30-80 \\
\text { до } 190-900\end{array}$ & $\begin{array}{l}\text { от } 30-90 \\
\text { до } 200-1000\end{array}$ & $\begin{array}{l}\text { от } 40-120 \\
\text { до } 750-850\end{array}$ & $\begin{array}{l}\text { от } 1000 \\
\text { до } 2400\end{array}$ & от 10 до 3300 \\
\hline
\end{tabular}

\begin{tabular}{|c|c|c|c|c|c|c|}
\hline \multirow{2}{*}{$\begin{array}{l}\text { № } \\
\Pi / \Pi\end{array}$} & \multirow[t]{2}{*}{ Параметр ДОэ } & \multicolumn{5}{|c|}{ 2. Голографические технологии } \\
\hline & & $\begin{array}{l}\text { Вогнутые } \\
\text { решетки [6] }\end{array}$ & $\begin{array}{l}\text { Вогнутые } \\
\text { решетки [7] }\end{array}$ & $\begin{array}{l}\text { Вогнутые } \\
\text { решетки [14] }\end{array}$ & $\begin{array}{l}\text { Аберраци- } \\
\text { онно-скоррек- } \\
\text { тированные } \\
\text { вогнутые } \\
\text { решетки для } \\
\text { полихромато- } \\
\text { ров с плоским } \\
\text { полем [16] }\end{array}$ & $\begin{array}{l}\text { Аберрационно- } \\
\text { скорректиро- } \\
\text { ванные вогну- } \\
\text { тые решетки } \\
\text { для монохро- } \\
\text { маторов [16] }\end{array}$ \\
\hline 2.1 & $\begin{array}{l}\text { Диапазон размеров } \\
\text { рабочей поверхности, } \\
\text { мм }\end{array}$ & от Ø15 до Ø90 & $\begin{array}{l}\text { от } 26 \times 26 \\
\text { до } \varnothing 114,3\end{array}$ & от Ø17 до Ø80 & $\begin{array}{l}\text { от } \varnothing 24 \\
\text { до } 52 \times 52\end{array}$ & $\begin{array}{l}\text { от } 20 \times 20 \\
\text { до } 65 \times 64\end{array}$ \\
\hline 2.2 & $\begin{array}{l}\text { Диапазон радиусов кри- } \\
\text { визны рабочей поверх- } \\
\text { ности, мм }\end{array}$ & от 80 до 6000 & $\begin{array}{l}\text { от } 112,14 \\
\text { до } 2217,6\end{array}$ & от 75 до 393 & от 55,5 до 191,4 & от 9९,९ до 257,6 \\
\hline 2.3 & $\begin{array}{l}\text { Диапазон стрелок про- } \\
\text { гиба рабочей поверхно- } \\
\text { сти, мм }\end{array}$ & от 0,01 до 4,10 & от 0,23 до 1,64 & от 0,24 до 4,46 & от 0,49 до 4,25 & от 0,84 до 6,12 \\
\hline 2.4 & $\begin{array}{l}\text { Диапазон простран- } \\
\text { ственных частот, мм-1 }\end{array}$ & от 50 до 3600 & от 83 до 4800 & от 149 до 2500 & от 240 до 1400 & от 600 до 1300 \\
\hline 2.5 & $\begin{array}{l}\text { Рабочий спектральный } \\
\text { диапазон, нм }\end{array}$ & $\begin{array}{l}\text { от } 190-400 \\
\text { до } 900-2500\end{array}$ & $\begin{array}{l}\text { от } 60-150 \\
\text { до } 4500-6000\end{array}$ & $\begin{array}{l}\text { от } 170-290 \\
\text { до } 1100-2500\end{array}$ & $\begin{array}{l}\text { от } 190-800 \\
\text { до } 850-1150\end{array}$ & $\begin{array}{l}\text { от } 190-800 \\
\text { до } 700-2000\end{array}$ \\
\hline
\end{tabular}


Таблица. Продолжение

\begin{tabular}{|c|c|c|c|c|c|c|c|}
\hline \multirow{2}{*}{$\begin{array}{l}\text { № } \\
\Pi / \Pi\end{array}$} & \multirow[t]{2}{*}{ Параметр Доэ } & \multicolumn{6}{|c|}{ 2. Голографические технологии (продлжение) } \\
\hline & & $\begin{array}{l}\text { Вогнутые } \\
\text { решетки для } \\
\text { спектрогра- } \\
\text { фов с плоским } \\
\text { полем [17] }\end{array}$ & $\begin{array}{l}\text { Вогнутые } \\
\text { решетки для } \\
\text { монохромато- } \\
\text { ров [17] }\end{array}$ & $\begin{array}{l}\text { Вогнутые } \\
\text { решетки } \\
\text { для моно- } \\
\text { хромато- } \\
\text { ров [18] }\end{array}$ & $\begin{array}{l}\text { Вогнутые } \\
\text { решетки с } \\
\text { плоским } \\
\text { полем [18] }\end{array}$ & $\begin{array}{l}\text { Вогнутые } \\
\text { решетки для } \\
\text { спектрогра- } \\
\text { фов на круге } \\
\text { Роуланда [19] }\end{array}$ & $\begin{array}{l}\text { Вогнутые } \\
\text { решетки для } \\
\text { монохромато- } \\
\text { ров [19] }\end{array}$ \\
\hline 2.6 & $\begin{array}{l}\text { Диапазон раз- } \\
\text { меров рабочей } \\
\text { поверхности, } \\
\text { мм }\end{array}$ & от Ø19 до Ø95 & $\begin{array}{l}\text { от } 24 \times 24 \\
\text { до Ø84 }\end{array}$ & $18 \times 18$ & $\begin{array}{l}\text { от Øз0 } \\
\text { до Ø45 }\end{array}$ & $\begin{array}{l}\text { от } 30 \times 30 \\
\text { до Ø90 }\end{array}$ & $\begin{array}{l}\text { от } 32 \times 32 \\
\text { до Ø90 }\end{array}$ \\
\hline 2.7 & $\begin{array}{l}\text { Диапазон } \\
\text { радиусов кри- } \\
\text { визны рабочей } \\
\text { поверхности, } \\
\text { мм }\end{array}$ & от 80 до 575 & $\begin{array}{l}\text { от } 74,73 \\
\text { до } 203,9\end{array}$ & 50 & от 55 до 100 & от 60 до 1500 & от 64 до 203,9 \\
\hline 2.8 & $\begin{array}{l}\text { Диапазон } \\
\text { стрелок про- } \\
\text { гиба рабочей } \\
\text { поверхности, } \\
\text { мм }\end{array}$ & от 0,52 до 4,94 & от 1,63 до 4,37 & 1,65 & $\begin{array}{l}\text { от } 1,13 \\
\text { до } 2,68\end{array}$ & от 0,34 до 8,02 & от 2,28 до 5,03 \\
\hline 2.9 & $\begin{array}{l}\text { Диапазон про- } \\
\text { странственных } \\
\text { частот, мм-1 }\end{array}$ & от 200 до 2197 & от 570 до 1500 & 1200 & от 164 до 954 & от 150 до 3600 & от 300 до 1200 \\
\hline 2.10 & $\begin{array}{l}\text { Рабочий } \\
\text { спектральный } \\
\text { диапазон, нм }\end{array}$ & $\begin{array}{l}\text { от } 190-400 \\
\text { до } 350-1050\end{array}$ & $\begin{array}{l}\text { от 190-700 } \\
\text { до } 1100-2500\end{array}$ & $\begin{array}{l}\text { от } 260 \\
\text { до } 450\end{array}$ & $\begin{array}{l}\text { от } 190-850 \\
\text { до } 1100-1900\end{array}$ & $\begin{array}{l}\text { от 100-300 } \\
\text { до 500-700 }\end{array}$ & $\begin{array}{l}\text { от } 100-300 \\
\text { до } 800-3200\end{array}$ \\
\hline
\end{tabular}

- коэффициенты неравномерности шага равны соответственно $\alpha=-0,00278$, $\beta=2,702 \cdot 10^{-6}, \Gamma=6,433 \cdot 10^{-8}, \Delta=6,182 \cdot 10^{-10}$, $\varepsilon=9,304 \cdot 10^{-12}$;

- угол падения 5,70, угол дифракции на 600 нм равен $19,157^{\circ}$, разворот нормали к поверхности изображения составляет $8,387^{\circ}$;

- $\quad$ изображение спектра длиной 28 мм формируется на вогнутой цилиндрической поверхности радиусом 47,6 мм;

- обратная линейная дисперсия 14,29 $\mathrm{HM} / \mathrm{MM}$;

- эквивалентное относительное отверстие $1: 1,75$.

Ширина аппаратной функции оптимизированной схемы на половине максимума составляет $100 ; 100$ и 105,6 мКм для 400, 600 и 800 нм, соответственно. С учетом обратной линейной дисперсии спектральный предел разрешения равен 1,43; 1,43 и 1,51 нм для тех же контрольных длин волн. Для сравнения ширина аппаратной функции исходной схемы составляет 102,4;
137,6 и 172,8 мкм. Спектральный предел в этом случае равен 1,$49 ; 2,00$ и 2,51 нм. Таким образом, коррекция остаточных аберраций, вводимая за счет использования переменного шага штрихов, позволяет повысить спектральное разрешение до 1,66 раза.

При световом диаметре решетки 58,6 мм получена максимальная расчетная стрелка прогиба её вогнутой рабочей поверхности - 4,54 мм. Как было показано выше, имеющиеся на практике нарезные (на основе применения классических делительных машин) и голографические технологии не могут решить задачу получения такой дифракционной структуры на столь крутой поверхности с большой стрелкой прогиба при сохранении высокой концентрации энергии в рабочем порядке дифракции и умеренного уровня рассеянного света. Это объясняется тем, что в нарезной технологии существуют принципиальные ограничения в конструкции и кинематике классических делительных машин, построенных по схеме Роуланда, а в голографической - ограничения по дифракционной эффективности. 
Для технологических задач изготовления дифракционных решеток с подобными и бо́льшими (до 50 мм) стрелками прогиба рабочих поверхностей предлагается использовать новое техническое решение - делительные машины маятникового типа, что открывает возможность формообразования светосильных нарезных дифракционных решеток на выпуклых сферических и асферических поверхностях [22]. Общий вид предлагаемой делительной машины маятникового типа представлен на рисунке.

При этом вогнутая светосильная неклассическая дифракционная решетка с рассчитанными выше параметрами может быть изготовлена путем прецизионного копирования (на основе использования термо- или фотополимерных композиций [23]) с выпуклой нарезной решеткиматрицы, изготавливаемой на делительной машине маятникового типа. При таком подходе обеспечивается сравнительно высокое качество изображения и высокая дифракционная эффективность в компактной и простой схеме спектрографа, а также низкая себестоимость и высокая производительность, что особенно важно при серийном производстве единственного оптического элемента (вогнутой дифракционной решетки-реплики) в оптической схеме и прибора в целом.

Следует отметить, что задача формообразования нарезных Доэ с большой стрелкой прогиба на выпуклых цилиндрических поверхностях оптимально решается при помощи делительной машины маятникового типа, принципы построения которой также защищены патентом PФ [24].

Важным этапом в технологии формообразования светосильных ДОЭ является аттестация их параметров, включающая в себя контроль их оптического качества и дифракционной эффективности в рабочих порядках и в заданном спектральном диапазоне. Контроль оптического качества целесообразно осуществлять интерферометрическими методами и средствами как наиболее информативными. По результатам расшифровки соответствующих интерферограмм получают количественную информацию об основных параметрах исследуемых образцов ДОэ функцию рассеяния точки, функцию рассеяния линии, коэффициент Штреля, среднеквадратичное отклонение. Для определения дифракционной эффективности (абсолютной и относительной) используются известные фотометрические методы и средства измерений $[25,26]$.
Укажем перспективные области использования светосильных ДОЭ:

- спектральная часть аппаратуры для дистанционного зондирования Земли и исследований космических объектов $[1,2]$;

- оптические компоненты систем для компрессии мощных лазерных импульсов [27];

- компактные изображающие спектрографы [3];

- спектрографы на основе использования вогнутых цилиндрических дифракционных решеток [4];

- преобразователи солнечной энергии на основе цилиндрических ДОЭ;

- в качестве прецизионных мастер-матриц при серийном и массовом производстве спектральной аппаратуры;

- система юстировочных сегментов синтезированных ДОЭ для обеспечения процессов прецизионной сборки и юстировки в телескопостроении $[28,29]$.

В заключение следует отметить:

- из рассмотренных четырех технологий в настоящее время только нарезная и голографическая являются наиболее освоенными для изготовления светосильных ДОЭ;

- в силу специфики спектральных приборов космического базирования (для задач дистанционного зондирования Земли и исследований космических объектов), а также спектральной аппаратуры, предназначенной для использования в условиях малых световых потоков и / или в коротковолновой области спектра, в частности, на основе цилиндрических дифракционных решеток, на данный момент для нарезных светосильных ДОэ альтернативы практически нет;

- для изготовления нарезных светосильных ДОэ наиболее оптимальным и перспективным решением является использование делительной техники маятникового типа;

- для серийного производства спектральной аппаратуры на основе использования светосильных вогнутых отражательных дифракционных решеток с заданной дифракционной эффективностью, а также преобразователей солнечной энергии на основе цилиндрических светосильных ДОЭ целесообразно изначально изготавливать мастер-матрицы на выпуклых поверхностях с последующим процессом репликации. 


\section{СПИСОК ЛИТЕРАТУРЫ}

1. Liu Ch., Straif Ch., Flügel-Paul Th., Zeitner U. D., Gross H. Optical design and tolerancing of a hyperspectral imaging spectrometer. Proc. SPIE. 2016. V. 9947. P. 994703-1-994703-9.

2. Kendrick S. E., Woodruff R. A., Hull T., Heap S. R., Kutyrev A., Danchi W., Purves L. Multiplexing in Astrophysics with a UV multi-object spectrometer on CETUS, a Probe-class mission study. Proc. SPIE. 2017; 10401: 1040111-1-1040111-9.

3. Мельников А. Н., Муслимов Э. Р. Анализ вариантов оптической схемы светосильного изображающего спектрографа, построенного на основе выпуклой голограммной дифракционной решетки. Оптический журнап. 2019; 86(3): 32-39.

4. Павлычева Н. К. Спектральные приборы с неклассическими дифракционными решетками. Казань: Изд-во КГТУ, 2003.

5. Корпорация «Hitachi Group». URL: http://www.hitachi-hightech.com.

6. Холдинг AO "Швабе» / AO «НПО ГИПО". Каталог оптической компонентной базы / URL: http://shvabe. com/about/company/ gosudarstvennyy-institut-prikladnoy-optiki/produktsiya-gipo/ opticheskie-materialy.

7. Корпорация "HORIBA Jobin Yvon Ltd." / URL: http://www.horiba.com/scientific/products/diffraction-gratings/.

8. Компания "ХолоГрэйт". URL: http://holograte.com/produktyi/ golograficheskie-difrakczionnyie-resheniya/difrakczionnyie-reshetki-dlyaspektralnyix-priborov.

9. Верхогляд А. Г., Завьялова М. А., Касторский Л. Б., Качкин А. Е., Кокарев С.А., Корольков В. П., Моисеев О. Ю., Полещук А. Г., Шиманский Р. В. Круговая лазерная записывающая система для изготовления дОЭ на сферических поверхностях. Интерэкспо ГЕО-Сибирь-2015. ХІ Междунар. науч. конгр.: Междунар. науч. конф. "СибОптика-2015": сб. материалов в 3 т. Новосибирск: СГУГит, 2015; 2: 62-68.

10. Компания "Altechna Company Croup». URL: http://www.altechna.com.

11. Xu D., Owen J. D., Papa J.C., Reimers J., Suleski T. J., Troutman J. R., Davies M. A., Thompson K. P., Rolland J. P. Design, fabrication, and testing of convex reflective diffraction gratings. Optics Express. 2017; 25(13): 15252-15267.

12. Sukegawa T., Okura Yu., Nakayasu T. Commercial availability of astronomical machined gratings by Canon. Proc. SPIE. 2018; 10706: 107063L-1107063L-6.

13. Zhou Q., Li L., Zeng L. A method to fabricate convex holographic gratings as master gratings for making flat-field concave gratings. Proc. SPIE. 2007; 6832: 68320W-1-68320W-9.

14. Компания Carl Zeiss Microscopy CmbH. URL: http://www.zeiss.de/gratings.

15. Компания Workshop of Photonics. URL: http://www.wophotonics.com.

16. Компания Shimadzu Corporation. URL: http://www.shimadzu.com/opt/

17. Компания Newport. URL: http://www.gratinglab.com

18. Компания Spectrum Scientific. URL: http://www.ssioptics.com

19. Компания GratingWorks. URL: http://www.gratingworks.com

20. Ai J., Du Q., Qin Zh., Liu J., Zeng X. Laser direct-writing lithography equipment system for rapid and $\mu \mathrm{m}$-precision fabrication on curved surfaces with large sag heights. Optics Express. 2018; 26(16): 20965-20974.

21. Мельников А. Н., Лукин А. В., Муслимов Э. Р. Расчет параметров неплоских дифракционных решеток для компактных светосильных спектрографов. Оптический журнал. 2019; 86(6): 7-10.

22. Патент РФ № 2691821. Делительная машина маятникового типа для изготовления штриховых структур на неппоских рабочих поверхностях/ Лукин А. В., Мельников А. Н.

23. Ахметов М. М., Белозёров А. Ф., Балоев В.А., Белокопытов А.А., Гайнутдинов И. С., Иванов В. П., Лукин А. В., Мельников А. Н., Могилюк И. А. Научно-производственный комплекс серийной прецизионной репликации элементов асферической и дифракционной оптики. Контенант. 2016; 15(3): 39-42.

24. Патент РФ на изобретение № 2687515. Делительная машина маятникового типа для изготовления штриховых структур на выпукяых цилиндрических поверхностях/Лукин А. В., Мельников А. Н.

25. Герасимов Ф. М., Яковлев Э.А. Дифракционные решетки/ Современные тенденции в технике спектроскопии. Новосибирск: Наука, 1982; 24-94.

\title{
ЭССЕНТОПТИКС (|() ESSENTOPTICS
}

\section{PHOTON RT}

\section{Спектрофотометр для Оптиков I Spectrophotometer for Coaters}

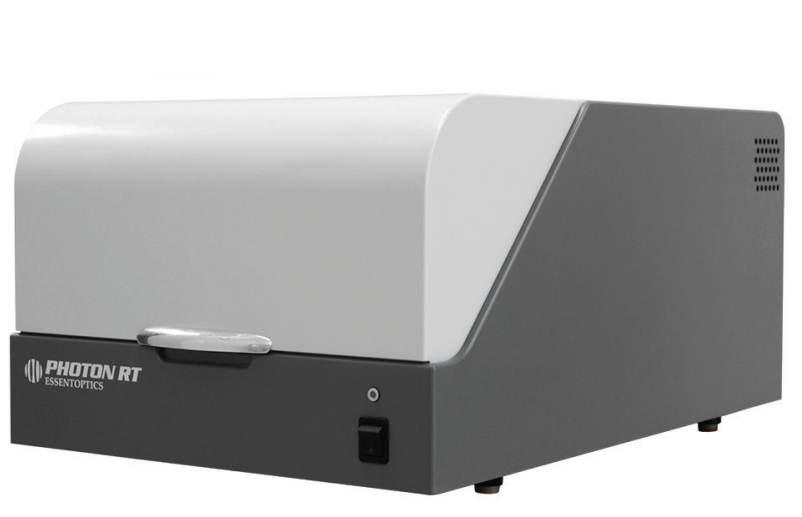

\section{$185-5200$ HM}

\author{
АВТОМАТИЧЕСКОЕ ИЗМЕРЕНИЕ \\ ПРОПУСКАНИЯ СЛОЖНЫХ \\ СКЛЕЕК И ПРИЗМ
}

\author{
UNATTENDED TRANSMITTANCE \\ MEASUREMENT OF COMPLEX \\ CEMENTED PRISMS
}




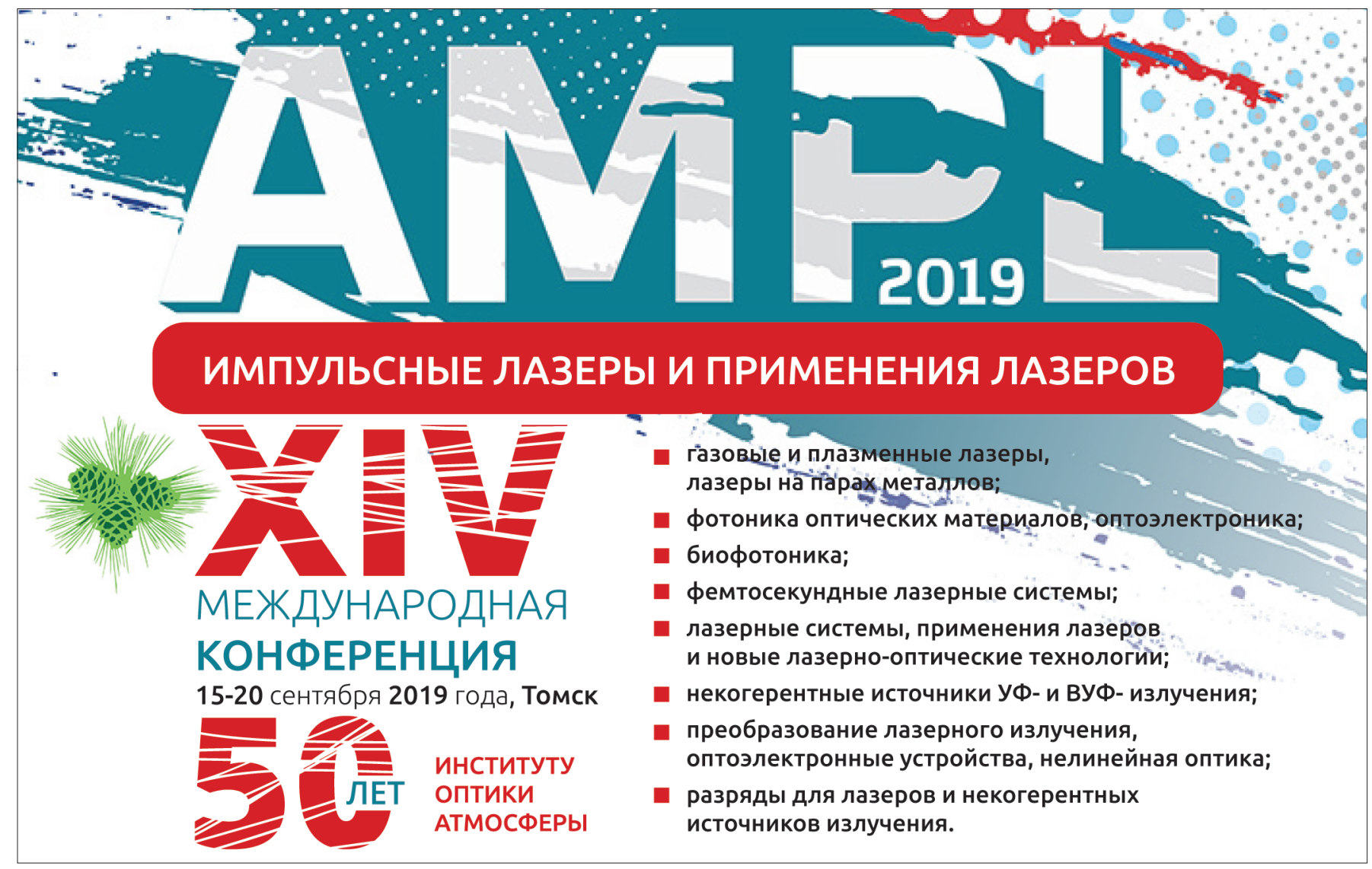

\section{ИЗДАТЕЛЬСТВО «ТЕХНОСФЕРА» ПРЕДСТАВЛЯЕТ КНИГУ:}

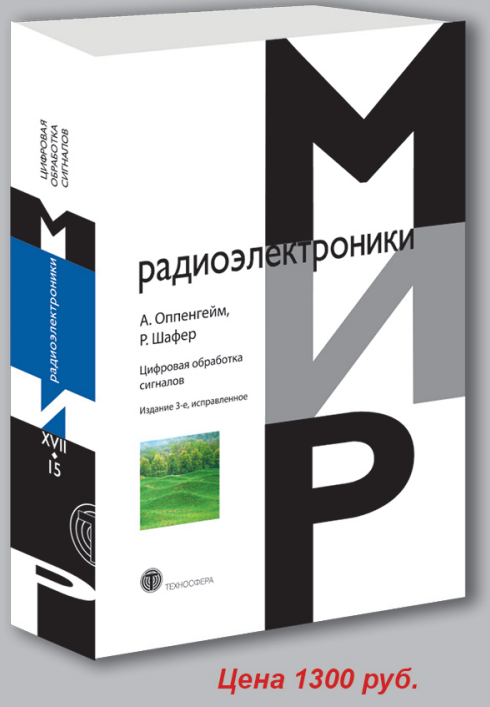

\section{Цифровая обработка сигналов}

Издание 3-е, исправленное

Оппенгейм А., Шабер Р.

при поддержке ОАО «РТИ»

перевод с англ. под ред. д.э.н., проф. С. Ф. Боева

Москва: ТЕХНОСФЕРА, 2019. - 1048 с., ISBN 978-5-94836-329-5

Предлагаемая вниманию читателя книга - третье переработанное издание всемирно известного классического учебника «Цифровая обработка сигналов», опубликованного в 1975 году. В ее основу лег развернутый курс по дискретной обработке сигналов, преподававшийся в течение ряда лет в Массачусетском технологическом институте.

Учебник посвящен математическим алгоритмам, реализуемым в цифровых системах. В нем опущены сложные доказательства математических утверждений, но все приемы и методы иллюстрированы многочисленными примерами и задачами.

Книга будет полезна как студентам, осваивающим предмет, так и инженерамразработчикам и системотехникам.

КАК ЗАКАЗАТЬ НАШИ КНИГИ?

125319, Москва, а/я 91; тел.: +7 495 234-0110; факс: +7 495 956-3346; e-mail: knigi@technosphera.ru; sales@technosphera.ru 
26. Palmer C., Loewen E. Diffraction Grating Handbook. Rochester: Newport Corporation, 2005.

27. Яковлев И. В. Стретчеры и компрессоры для сверхмощных лазерных систем. Квантовая эпектроника. 2014; 44(5): 393-414.

28. Балоев В.А., Иванов В. П., Ларионов Н. П., Лукин А. В., Мельников А. Н., Скочилов А. Ф., Чугунов Ю. П., Ураскин А. М. Прецизионный метод контроля юстировки двухзеркальных телескопов на основе использования системы кольцевых синтезированных голограмм. Оптический журнап. 2012; 79(3): 56-64.

29. Белозёров А., Ларионов Н., Лукин А., Мельников А. Осевые синтезированные голограммные оптические элементы: история развития, применения. Часть І. Фотоника. 2014; 46(4): 12-32.

\section{REFERANCE}

1. Liu Ch., Straif Ch., Flügel-Paul Th., Zeitner U. D., Gross H. Optical design and tolerancing of a hyperspectral imaging spectrometer. Proc. SPIE. 2016. V. 9947. P. 994703-1-994703-9.

2. Kendrick S. E., Woodruff R. A., Hull T., Heap S. R., Kutyrev A., Danchi W., Purves L. Multiplexing in Astrophysics with a UV multi-object spectrometer on CETUS, a Probe-class mission study. Proc. SPIE. 2017; 10401: 1040111-1-1040111-9.

3. Mel'nikov A. N., Muslimov E. R. Analiz variantov opticheskoj skhemy svetosil'nogo izobrazhayushchego spektrografa, postroennogo na osnove vypukloj gologrammnoj difrakcionnoj reshetki. Opticheskij zhurnal. 2019; 86(3): 32-39.

4. Pavlycheva N. K. Spektral'nye pribory s neklassicheskimi difrakcionnymi reshetkami. Kazan': Izd-vo KCTU. 2003.

5. URL: http://www.hitachi-hightech.com.

6. URL: http://shvabe. com/about/company/gosudarstvennyy-institutprikladnoy-optiki/produktsiya-gipo/opticheskie-materialy.

7. URL: http://www.horiba.com/scientific/products/diffractiongratings/.

8. URL: http://holograte.com/produktyi/golograficheskiedifrakczionnyie-resheniya/difrakczionnyie-reshetki-dlya-spektralnyixpriborov.

9. Verhoglyad A. G., Zav'yalova M. A., Kastorskij L. B., Kachkin A. E., Kokarev S. A., Korol'kov V. P., Moiseev O. Yu., Poleshchuk A. G., Shimanskij R. V. Krugovaya lazernaya zapisyvayushchaya sistema dlya izgotovleniya DOE na sfericheskih poverhnostyah. Interekspo CEOSibir'-2015. HI Mezhdunar. nauch. kongr.: Mezhdunar. nauch. konf. 'SibOptika-2015': sb. materialov v 3 t. Novosibirsk: SGUGiT, 2015; 2: 62-68.

10. URL: http://www.altechna.com.

11. Xu D., Owen J. D., Papa J. C., Reimers J., Suleski T. J., Troutman J. R., Davies M. A., Thompson K. P., Rolland J. P. Design, fabrication, and testing of convex reflective diffraction gratings. Optics Express. 2017;

\section{5(13): 15252-15267.}

12. Sukegawa T., Okura Yu., Nakayasu T. Commercial availability of astronomical machined gratings by Canon. Proc. SPIE. 2018; 10706: 107063L-1-107063L-6.

13. Zhou Q., Li L., Zeng L. A method to fabricate convex holographic gratings as master gratings for making flat-field concave gratings. Proc SPIE. 2007: 6832: 68320W-1-68320W-9.

14. URL: http://www.zeiss.de/gratings.

15. URL: http://www.wophotonics.com

16. URL: http://www.shimadzu.com/opt/

17. URL: http://www.gratinglab.com

18. URL: http://www.ssioptics.com

19. URL: http://www.gratingworks.com

20. Ai J., Du O., Oin Zh., Liu J., Zeng X. Laser direct-writing lithography equipment system for rapid and $\mu \mathrm{m}$-precision fabrication on curved surfaces with large sag heights. Optics Express. 2018; 26(16): 20965-20974.

21. Mel'nikov A. N., Lukin A. V., Muslimov E. R. Raschet parametrov neploskih difrakcionnyh reshetok dlya kompaktnyh svetosil'nyh spektrografov. Opticheskij zhurnal. 2019; 86(6): 7-10.

22. Patent RF № 2691821. Delitel'naya mashina mayatnikovogo tipa dlya izgotovleniya shtrihovyh struktur na neploskih rabochih poverhnostyah/Lukin A. V., Mel'nikov A. N.

23. Ahmetov M. M., Belozyorov A. F., Baloev V. A., Belokopytov A. A. Gajnutdinov I. S., Ivanov V. P., Lukin A. V., Mel'nikov A. N., MogiIyuk I. A. Nauchno-proizvodstvennyj kompleks serijnoj precizionnoj replikacii elementov asfericheskoj i difrakcionnoj optiki. Kontenant. 2016; 15(3): 39-42

24. Patent RF № 2687515. Delitel'naya mashina mayatnikovogo tipa dlya izgotovleniya shtrihovyh struktur na vypuklyh cilindricheskih poverhnostyah/ Lukin A. V., Mel'nikov A.N.

25. Gerasimov F. M., Yakovlev E. A. Difrakcionnye reshetki/Sovremennye tendencii v tekhnike spektroskopii. Novosibirsk: Nauka, 1982; 24-94.

26. Palmer C., Loewen E. Diffraction Grating Handbook. Rochester: Newport Corporation, 2005.

27. Yakovlev I. V. Stretchers and compressors for heavy duty laser systems. Quantum Electronics. 2014; 44(5): 393-414.

28. Baloev V. A., Ivanov V. P., Larionov N. P., Lukin A. V., Mel'nikov A. N., Skochilov A. F., Chugunov Yu. P., Uraskin A. M. Precizionnyj metod kontrolya yustirovki dvuhzerkal'nyh teleskopov na osnove ispol'zovaniya sistemy kol'cevyh sintezirovannyh gologramm. Opticheskij zhurnal. 2012; 79(3): 56-64.

29. Belozyorov A. F., Larionov N. P., Lukin A. V., Mel'nikov A. N. Osevye sintezirovannye gologrammnye opticheskie elementy: istoriya razvitiya, primeneniya. Part I. Photonics Russia. 2014; 4 (46): 12-32.

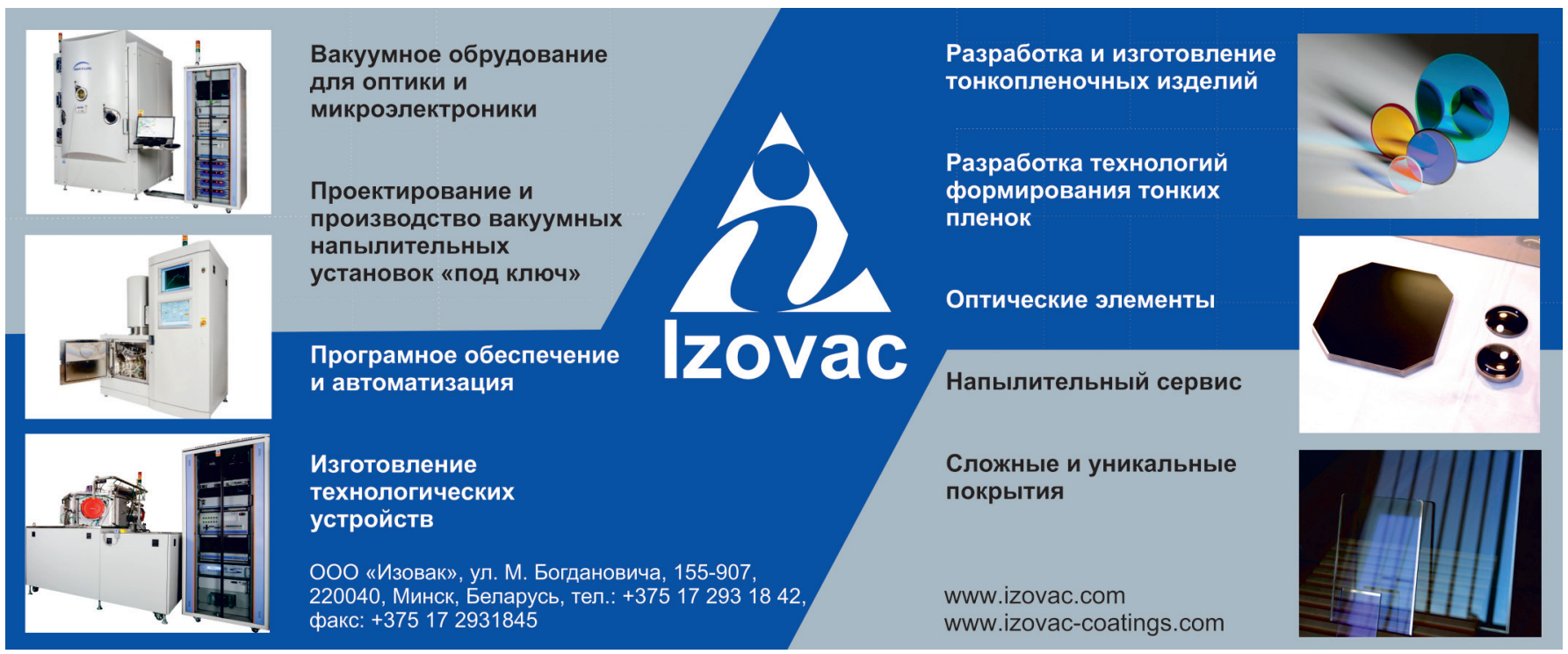

